Article

\title{
A Three-Bridge IPT System for Different Power Levels Conversion under CC/CV Transmission Mode
}

\author{
Bingyang Luo, Yatao Shou, Jianghua Lu, Ming Li, Xiangtian Deng * and Guorong Zhu
}

School of Automation, Wuhan University of Technology, Wuhan 430000, China

* Correspondence: dengxt@whut.edu.cn; Tel.: +86-189-7140-0950

Received: 25 July 2019; Accepted: 8 August 2019; Published: 9 August 2019

check for updates

\begin{abstract}
This paper proposes an inductive power transfer (IPT) system with three-bridge switching compensation topology. With the proposed IPT topology, the equivalent circuit and the resonant condition are analyzed to achieve the load-independent constant current (CC) and load-independent constant voltage (CV) outputs. On this basis, multiple power levels can be achieved under CC/CV conditions by bridge arm switching, which makes it possible to complete charging tasks for multiple power level electric vehicles (EV) without switching the IPT system. A circuit simulation was built to verify the different power level switching effects of the structure. A $3.3 \mathrm{~kW}$ IPT system was designed to verify the proposed structure. At the rated output power, the experimental efficiency was up to $92.04 \%$ and $91.21 \%$ in CC and CV output modes, respectively.
\end{abstract}

Keywords: inductive power transfer (IPT); three-bridge switching; constant current (CC); constant voltage $(\mathrm{CV})$; fixed frequency

\section{Introduction}

The IPT (inductive power transfer) technology uses a loosely coupled transformer (LCT) structure with primary and secondary coils to achieve non-contact energy transfer. Due to the safety, stability, and lower maintenance cost of this structure, IPT systems are receiving more and more attention and research in many fields, such as consumer electrics, biomedical implants, and electric vehicles (EVs) [1-3]. As shown in Figure 1, an IPT system mainly consists of five parts: High-frequency inverter, loosely coupled transformer with primary and secondary coils, primary and secondary compensation networks, rectifier, and battery load.

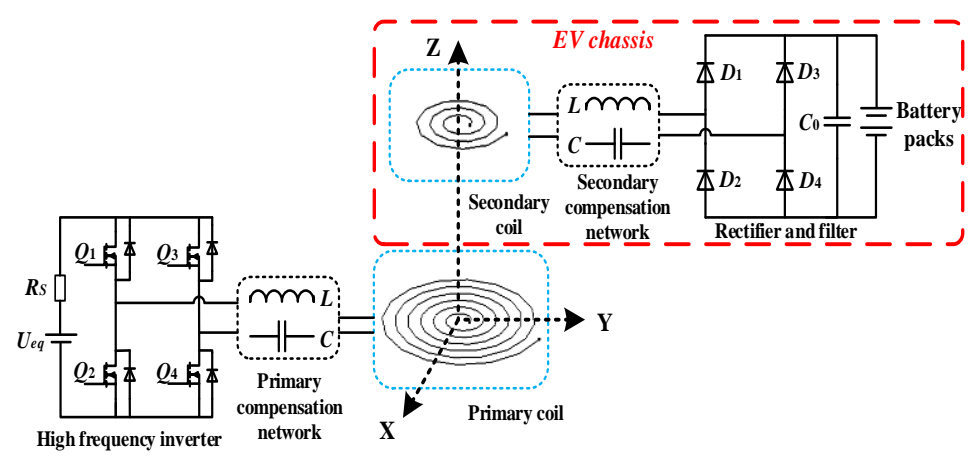

Figure 1. Schematic diagram of an inductive power transfer (IPT) system.

The existence of an air gap between the primary and secondary coils of the IPT system will lead to large leakage inductance. In order to improve the system efficiency and power transfer capability, the compensation network will be used to resonate with the leakage inductance [4]. The four basic 
topologies (series-series, series-parallel, parallel-series, and parallel- parallel) are the most widely studied, and the SS (series-series) topology is one of the most widely used topologies due to its simple structure and primary capacitance that is independent of the variation of the coupling coefficient [5-7].

As lithium batteries are the main load batteries in the field of electric vehicles, the research on the charging characteristics of lithium batteries is of great significance for the design of IPT systems [8]. The typical charging process of the lithium battery for EVs is shown in Figure 2. From Figure 2, the charging state could be divided into two steps: Constant current (CC) mode and constant voltage (CV) mode [9]. In CC mode, the current is constant and the voltage gradually rises. When the voltage rises to the rated value, it will become stable and the current will gradually decrease until the state of charge ends [10].

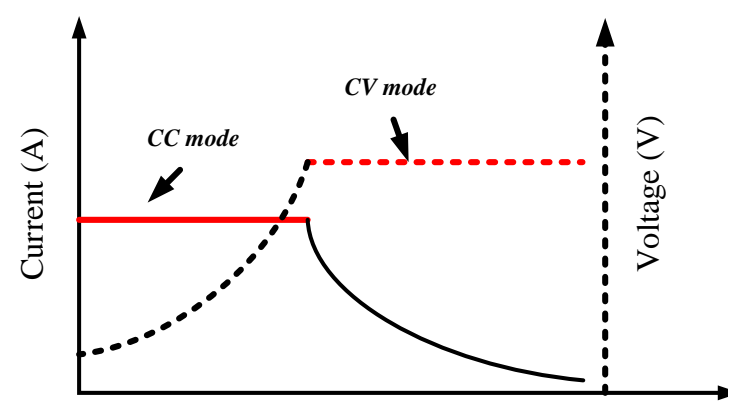

Time (s)

Figure 2. Process of lithium-ion battery cell charging.

In order to obtain load-independent $\mathrm{CC} / \mathrm{CV}$ transmission characteristics, there are currently three main methods: A back-end DC/DC converter, variable operating frequency control, and special tuning methods for resonant tank network in IPT systems. However, adding a DC/DC converter not only increases the cost, but also introduces additional inevitable losses. The method involving changing switching-frequency increases the complexity of system control and reduces system stability due to frequency bifurcation [11-13]. In J. Lu's paper [14], the resonant conditions for obtaining CC/CV transmission characteristics by T-equivalence and pi-equivalence are introduced in detail. Using this method, the load-independent $\mathrm{CC} / \mathrm{CV}$ transmission condition of many typical compensation networks can be analyzed easily.

In addition, different charging objects have different charging power level requirements in $\mathrm{CC} / \mathrm{CV}$ mode $[15,16]$. For example, the charging power level applied to a bus and a car by the IPT system must be different. The traditional IPT systems only perform charging tasks for a fixed power level, which necessarily has certain limitations $[17,18]$.

To meet multi-power level charging flexibility in CC/CV mode, this paper adopted a three-bridge arm switching concept to perform different modes conversion under constant frequency. Switching from CC to CV mode was achieved by designing two SS compensation networks with the same compensating components on the secondary side, and the primary side compensating components were transformed by switching the working bridge arm. One of the SS compensation networks was designed for the CC transmission mode while the other was designed for the CV transmission mode. Since the voltage gain and transconductance in both CC and CV modes can be specified by parameter design, the specific value of the output power can also be obtained, which means that the structure can achieve two different power-level charging. This paper establishes a mathematical model of system output power in CC/CV mode and illustrates the designability of different power level outputs. The resonance conditions of the CC and CV modes were analyzed by the leakage inductance model. The verification of theoretical analysis was completed by establishing an IPT system under MATLAB/Simulink. Furthermore, an experiment platform was built to verify the simulation results. 


\section{System Structure and Analysis}

\subsection{System Structure}

As shown in Figure 3, the proposed IPT system includes a three-phase inverter, two SS compensation topologies with a shared secondary compensation capacitor, a three-winding loosely coupled transformer with two primary coils and one secondary coil, and an uncontrolled rectifier with a capacitor output filter. $\mathrm{Q}_{1}-\mathrm{Q}_{6}$ and $\mathrm{D}_{1}-\mathrm{D}_{4}$ represent six switching power devices of the primary side inverter and four diodes of the secondary side rectifier, respectively. $C_{\mathrm{p} 1}$ and $C_{\mathrm{p} 2}$ are the primary compensation capacitors, while $C_{\mathrm{s}}$ is the secondary compensation capacitor. $L_{\mathrm{p} 1}$ and $L_{\mathrm{p} 2}$ represent the self-inductance of the two transmitting coils on the primary side, and $L_{\mathrm{s}}$ represents the self-inductance of the receiving coil. $M_{\mathrm{p} 1 \mathrm{p} 2}, M_{\mathrm{p} 1 \mathrm{~s}}$, and $M_{\mathrm{p} 2 \mathrm{~s}}$ represent the mutual inductance between $L_{\mathrm{p} 1}$ and $L_{\mathrm{p} 2}$, $L_{\mathrm{p} 1}$ and $L_{\mathrm{s}}$, and $L_{\mathrm{p} 2}$ and $L_{\mathrm{s}}$, respectively. $U_{\mathrm{DC}}$ and $U_{\mathrm{L}}$ are system input and output DC voltages, respectively. $R_{\mathrm{L}}$ represents battery load.

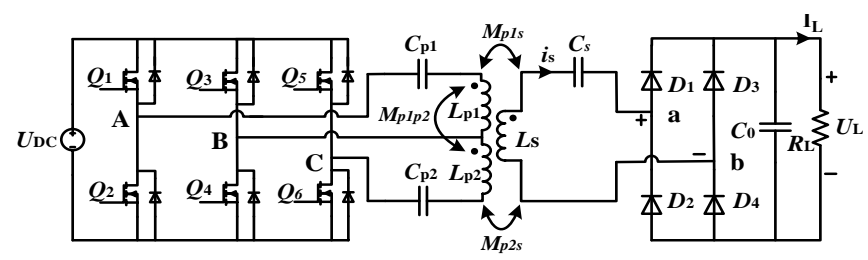

Figure 3. Three-bridge arm-switching IPT system structure.

\subsection{Mode}

The equivalent circuit of Figure 3 for achieving CC output mode is shown in Figures 4 and 5. The system structure shown in Figure 4 was designed to get $\mathrm{CC}$ charging mode. This means the power devices $Q_{5}$ and $Q_{6}$ are OFF all the time in this mode, and $Q_{1}-Q_{4}$ form a single-phase full-bridge inverter. Actually, Figure 4 shows a SS-compensated IPT system. The FHA (fundamental harmonics analysis) method was taken in this paper to simplify the analysis of the output characteristics. In this case, the output voltage of the inverter $U_{A B}$ and the equivalent ac load $R_{e q}$ are derived as

$$
\begin{aligned}
& U_{A B}=\frac{2 \sqrt{2}}{\pi} U_{D C} \\
& R_{e q}=\frac{8}{\pi^{2}} R_{L}
\end{aligned}
$$

The equivalent model of the SS resonant circuit with reference to the primary side is shown in Figure 5. The symbols "' " means that the equivalence was measured from the secondary side to the primary side. $L_{\mathrm{kp} 1}$ and $L_{\mathrm{ks}}^{\prime}$ means the leakage-inductance of the primary and secondary coil, respectively, and $L_{m 1}$ represents the magnetizing inductance. $L_{\mathrm{kp} 1}$ and $C_{\mathrm{p} 1}$ are equivalent to capacitor $C_{\text {eq1 }}$. $C_{S}^{\prime}$ shows the equivalent capacitance of the secondary side compensation capacitance converted to the primary side. $R_{\text {eq }}^{\prime}$ indicates that the equivalent resistance was converted from the secondary side to the primary side. $Z_{\mathrm{Rcc}}, Z_{\mathrm{m} 1}$, and $Z_{\text {incc }}$ represent the impedance.

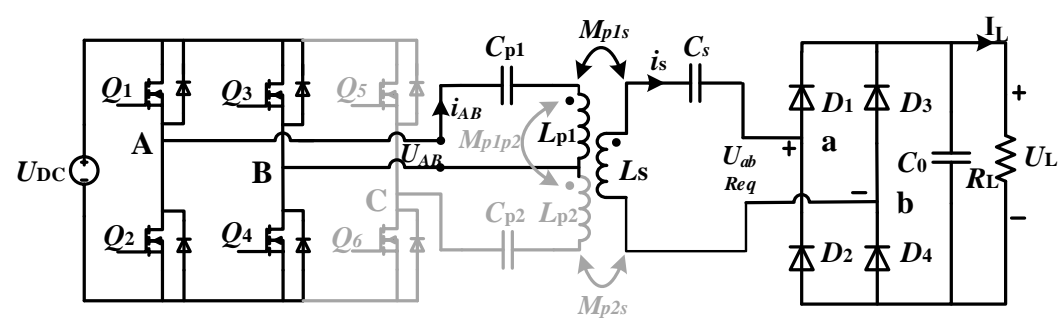

Figure 4. IPT system structure diagram in constant current (CC) mode. 


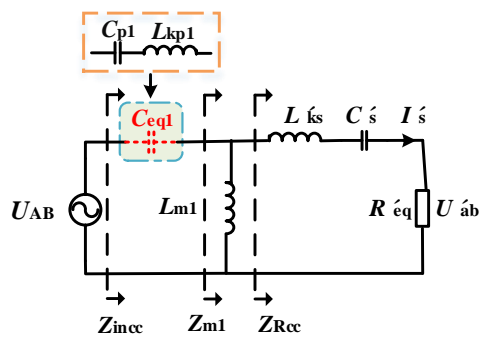

Figure 5. Equivalent circuit of Figure 4 with reference to the primary side.

Some of the parameters are shown in the following formula, such as turns ratio, $n_{c c}$, and coupling coefficient, $k_{c c}$,

$$
n_{c c}=\sqrt{\frac{L_{s}}{L_{p 1}}}, k_{c c}=\frac{M_{p 1 s}}{\sqrt{L_{p 1} L_{s}}} .
$$

The equivalent variables of Figure 5 are expressed as:

$$
\begin{aligned}
& L_{k p 1}=\left(1-k_{c c}\right) L_{p 1} \\
& L_{m 1}=k_{c c} L_{p 1} \\
& L_{k s}^{\prime}=\frac{\left(1-k_{c c}\right) L_{s}}{n_{c c}^{2}} \\
& C_{s}^{\prime}=n_{c c}^{2} C_{s} \\
& R_{e q}^{\prime}=\frac{R_{e q}}{n_{c c}^{2}} \\
& U_{a b}^{\prime}=\frac{U_{a b}}{n_{c c}}
\end{aligned}
$$

In order to achieve CC output, the following resonant conditions [19] are designed.

$$
\begin{aligned}
& \frac{1}{C_{e q 1}}=\frac{1}{C_{p 1}}-\omega_{c c}^{2} L_{k p 1} \\
& \omega_{c c}^{2}=\frac{1}{L_{m 1} C_{e q 1}}
\end{aligned}
$$

where $\omega_{c c}$ represents the resonant frequency in CC transmission mode.

Then, the voltage gain of the resonant network shown in Figure 5 can be expressed as

$$
G_{c c}=\frac{U_{a b}}{U_{A B}}=\frac{n_{c c} U_{a b}^{\prime}}{U_{A B}}=n_{c c} \frac{\left|R_{e q}^{\prime}\right|}{\left|Z_{\text {Rcd }}\right|} \frac{\left|Z_{m 1}\right|}{\left|Z_{\text {incd }}\right|} .
$$

The DC voltage transfer ratio is derived as

$$
M_{c c}=\frac{U_{L}}{U_{D C}}=\frac{\frac{\pi}{2 \sqrt{2}} U_{a b}}{\frac{\pi}{2 \sqrt{2}} U_{A B}}=G_{c c}=\frac{8 R_{L}}{\mathrm{j} \pi^{2} \omega_{c c} n_{c c} L_{m 1}} .
$$

Therefore, the system output voltage and output current under the CC mode can be characterized as

$$
\begin{aligned}
& U_{L(C C)}=\frac{8 R_{L} U_{D C}}{\mathrm{j} \pi^{2} \omega_{c c} n_{c c} L_{m 1}}, \\
& I_{L(C C)}=\frac{8 U_{D C}}{\mathrm{j} \pi^{2} \omega_{c c} n_{c c} L_{m 1}} .
\end{aligned}
$$

Moreover, the system output power of the CC mode is available.

$$
P_{(C C)}=R_{L} I_{L(C C)}^{2} .
$$

From Equation (8), it can be seen that the output current was constant and load independent. 


\subsection{Mode}

The equivalent circuit of CV mode in IPT system is shown in Figures 6 and 7. In this mode, the power devices $Q_{1}$ and $Q_{2}$ are $O F F$ all the time, and $Q_{3}-Q_{6}$ form a single-phase full-bridge inverter. Furthermore, Figure 6 is modeled as Figure 7 based on the FHA method. It can be seen that Figure 7 is essentially a T-circuit. In this case, the output voltage of the inverter $U_{B C}$ is derived as

$$
U_{B C}=\frac{2 \sqrt{2}}{\pi} U_{D C}
$$

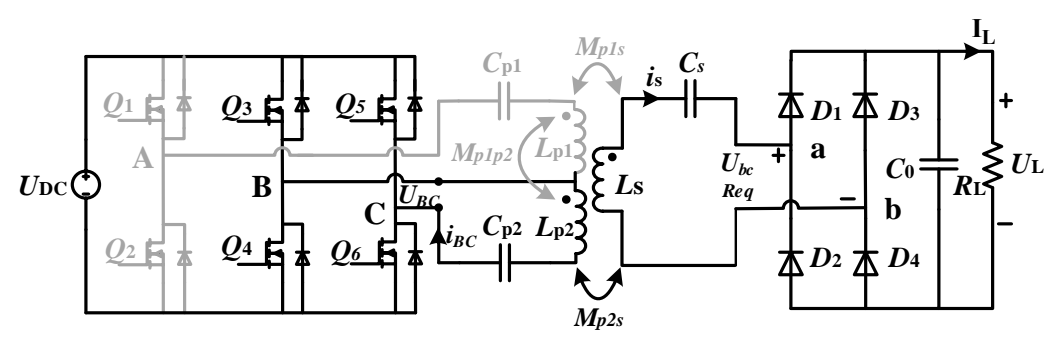

Figure 6. IPT system structure diagram in constant voltage (CV) mode.

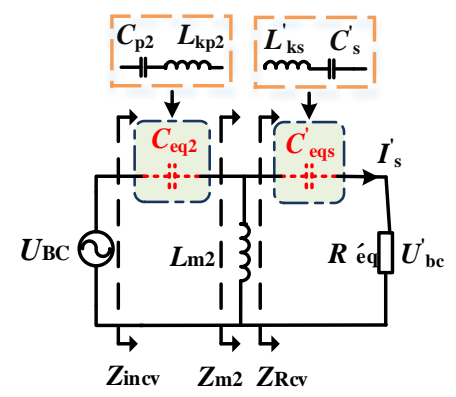

Figure 7. Equivalent circuit of Figure 6 with reference to the primary side.

The turns ratio of secondary to primary side and the coupling coefficient are defined as

$$
n_{c v}=\sqrt{\frac{L_{s}}{L_{p 2}}}, k_{c v}=\frac{M_{p 2 s}}{\sqrt{L_{p 2} L_{s}}} .
$$

As shown in Figure 7, the equivalent variables are derived as

$$
\begin{aligned}
& L_{k p 2}=\left(1-k_{c v}\right) L_{p 2} \\
& L_{m 2}=k_{c v} L_{p 2} \\
& L_{k s}^{\prime}=\frac{\left(1-k_{c v}\right) L_{s}}{n_{c v}^{2}} \\
& C_{s}^{\prime}=n_{c v}^{2} C_{s} \\
& R_{e q}^{\prime}=\frac{R_{e q}}{n_{c v}^{2}} \\
& U_{b c}^{\prime}=\frac{U_{b c}}{n_{c v}}
\end{aligned}
$$

According to J. Lu's paper [19], the resonance condition for realizing CV output is given by

$$
\begin{aligned}
\frac{1}{C_{e q 2}} & =\frac{1}{C_{C 2}}-\omega_{c v}^{2} L_{k p 2} \\
\frac{1}{C_{e q s}^{\prime}} & =\frac{1}{C_{s}^{\prime}}-\omega_{c v}^{2} L_{k s}^{\prime} \\
\omega_{c v}^{2} & =\frac{1}{L_{m 2}\left(C_{e q 2}+C_{e q s}^{\prime}\right)}
\end{aligned}
$$

where $\omega_{c v}$ represents the resonant frequency in CV transmission mode. 
Then, the voltage gain of the resonant network shown in Figure 7 can be expressed as

$$
G_{c v}=\frac{U_{b c}}{U_{B C}}=\frac{n_{c c} U_{b c}^{\prime}}{U_{B C}}=n_{c c} \frac{\left|R_{e q}^{\prime}\right|}{\left|Z_{R c v}\right|} \frac{\left|Z_{m 2}\right|}{\left|Z_{\text {incv }}\right|}
$$

According to Equation (10), the DC voltage transfer ratio is derived as

$$
M_{c v}=\frac{U_{L}}{U_{D C}}=\frac{\frac{\pi}{2 \sqrt{2}} U_{b c}}{\frac{\pi}{2 \sqrt{2}} U_{B C}}=G_{c v}=\frac{n_{c v} C_{e q 2}}{C_{e q s}^{\prime}} .
$$

Therefore, the system output voltage and output current under the CV mode can be characterized as

$$
\begin{aligned}
& U_{L(C V)}=\frac{n_{c v} C_{e q 2} U_{D C}}{C_{e q s}^{\prime}}, \\
& I_{L(C V)}=\frac{n_{c v} C_{e q 2} U_{D C}}{R_{L} C_{e q s}^{\prime}} .
\end{aligned}
$$

Moreover, the system output power of the CV mode is available.

$$
P_{(C V)}=\frac{U_{L(C V)}^{2}}{R_{L}}
$$

From Equation (16), it can be seen that the output voltage is constant and load independent.

Combining the theoretical analysis of the above-two transmission modes, it could be known that the three-bridge inverter structure could realize the conversion from CC mode to CV mode by switching the working bridge arm under the fixed-frequency.

Combining the Equations (9) and (18), it can be seen that the output power of both CC mode and $\mathrm{CV}$ mode is related to the load resistance $R_{\mathrm{L}}$, and the specific output powers in CC and CV modes can be obtained by designing the rated load resistance at the switching time. Combined with the parameter design, the CC/CV working mode was switched by changing the bridge arm, and different power level outputs were also completed. Therefore, the structure can achieve different power level switching based on CC/CV conditions.

\section{Simulation and Experiment}

\subsection{Parameter Design}

The LCT model parameters based on CC/CV transmission mode selected in this paper were obtained through Maxwell. Figure 8 shows the specific model dimensions of the LCT structure. The transmission coils and the corresponding ferrites were square structures, the side length of the primary side was $250 \mathrm{~mm}$, the side length of the auxiliary section was $330 \mathrm{~mm}$, and the air gap between the primary and secondary coils was $110 \mathrm{~mm}$. To facilitate the parameter design process, both the primary and secondary self-inductance of LCT were designed to be equal, that is, the value of the turns-ratio $n$ was 1 . Through the finite element simulation of the LCT structure, the specific parameter values of the LCT were obtained as shown in Table 1. 


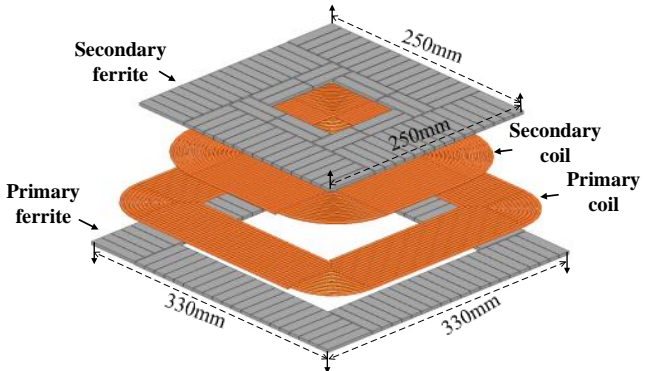

(a)

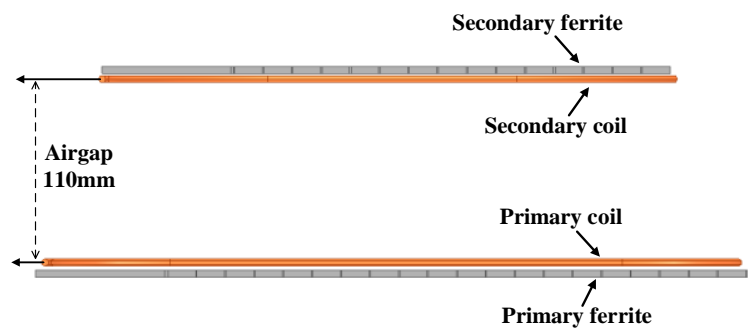

(b)

Figure 8. Loosely coupled transformer (LCT) structure in IPT system with (a) main view and (b) front view.

Table 1. Parameters in IPT system.

\begin{tabular}{cc}
\hline Parameters & Value \\
\hline$U_{\mathrm{DC}}$ & $220 \mathrm{~V}$ \\
$U_{\mathrm{L}}$ & $260 \mathrm{~V}$ \\
$k$ & 0.2 \\
The LCT coil inductance $\left(L_{\mathrm{p} 1}=L_{\mathrm{p} 2}=L_{\mathrm{S}}\right)$ & $120 \mu \mathrm{H}$ \\
The resonance frequency $f_{\mathrm{cc}} / f_{\mathrm{cv}}$ & $85 \mathrm{kHz}$ \\
The system output power $(P)$ & $3.3 \mathrm{~kW}$ \\
\hline
\end{tabular}

According to Equation (4), the primary compensation capacitor in the CC mode is calculated as

$$
C_{p 1}=\frac{1}{\omega_{c c}^{2}\left(L_{m 1}+L_{k p 1}\right)}=\frac{1}{\omega_{c c}^{2} L_{p 1}}=29.216 \mathrm{nF} .
$$

By using Equations (11) and (12), it was found that the SS topology primary compensation capacitor, $C_{\mathrm{p} 2}$, in the $\mathrm{CV}$ mode and the fixed secondary compensation capacitor, $C_{\mathrm{s}}$, could be obtained separately.

$$
\begin{gathered}
C_{p 2}=\frac{1}{\frac{1}{C_{e q 2}}+\omega_{c v}^{2} L_{k p 2}}=35.138 \mathrm{nF} . \\
C_{s}^{\prime}=\frac{1}{\frac{1}{C_{e q s}^{\prime}}+\omega_{c v}^{2} L_{k s}^{\prime}}=28.308 \mathrm{nF} .
\end{gathered}
$$

\subsection{Simulation Results}

Through the parameter design of the previous section, the simulation verification based on transconductance and voltage gain was completed. Figure 9 shows the transconductance versus system operating frequency for various load resistances. It can be seen that the transconductance was independent of the load when the IPT system operated at $85 \mathrm{kHz}$. Figure 10 shows the AC voltage gain versus system operating frequency for various load resistances. It can be seen that the voltage gain was independent of the load when the IPT system operated at $85 \mathrm{kHz}$. 


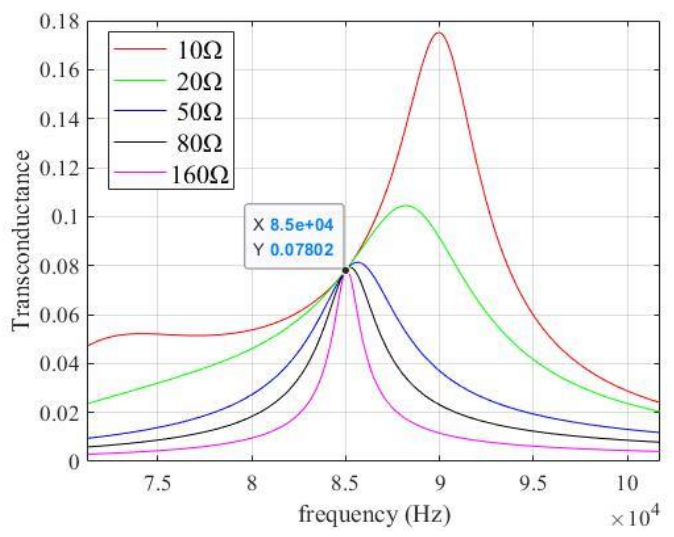

Figure 9. Transconductance with respect to frequency for different load conditions.

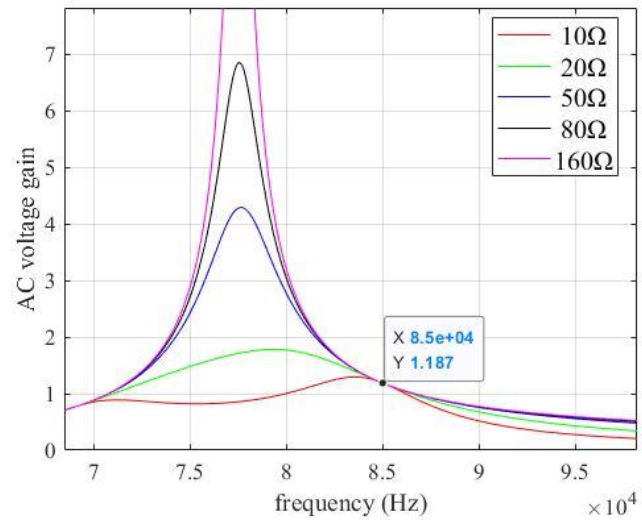

Figure 10. Voltage gain with respect to frequency for different load conditions.

According to the previous analysis, by determining the rated load resistance, $\mathrm{R}_{\mathrm{L}}$, at the time of switching, two different output powers were realized while switching from CC to CV mode. In order to prove the previous analysis, a three-bridge switching IPT system circuit under MATLAB/Simulink was built. The simulation results are shown in Figure 11. From the previous mathematical model of the output power of $\mathrm{CC} / \mathrm{CV}$ mode, it can be known that the output power of $\mathrm{CC} / \mathrm{CV}$ mode is different except for the specific load resistance (The specific load resistance value can be calculated when P1 is equal to P2). Figure 11a shows that the bridge arm switching process did not change the system output power under the specific load resistance condition as described above, and the IPT system had a system output power of $3.3 \mathrm{~kW}$ in both CC and CV modes. Figure $11 \mathrm{~b}$ shows that under other rated load resistance condition, the bridge arm switching process changed the system output power from 2.8 to $3.9 \mathrm{~kW}$.

The time (t1) in Figure 11 represents the switching load resistance under the CC mode condition, in which the current changed by $0.5 \mathrm{~A}$. The time (t2) in Figure 11 represents the switching of the working arm so that the system was switched from the CC mode to the CV mode. The time (t3) in Figure 11 represents the switching load resistance under the $\mathrm{CV}$ mode condition. It can be seen from the simulation results that the CC-to-CV mode switching was realized by changing the working arm, and two specific system output powers in CC/CV mode were also obtained. 


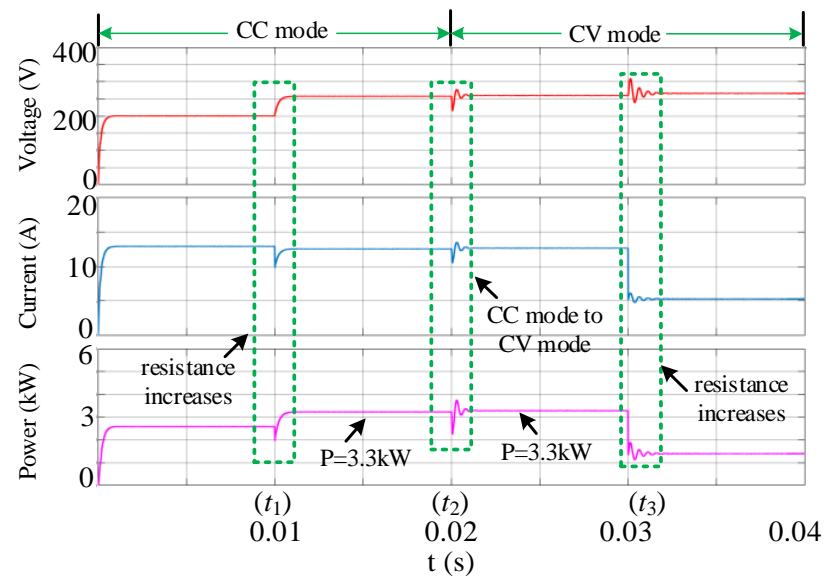

(a)

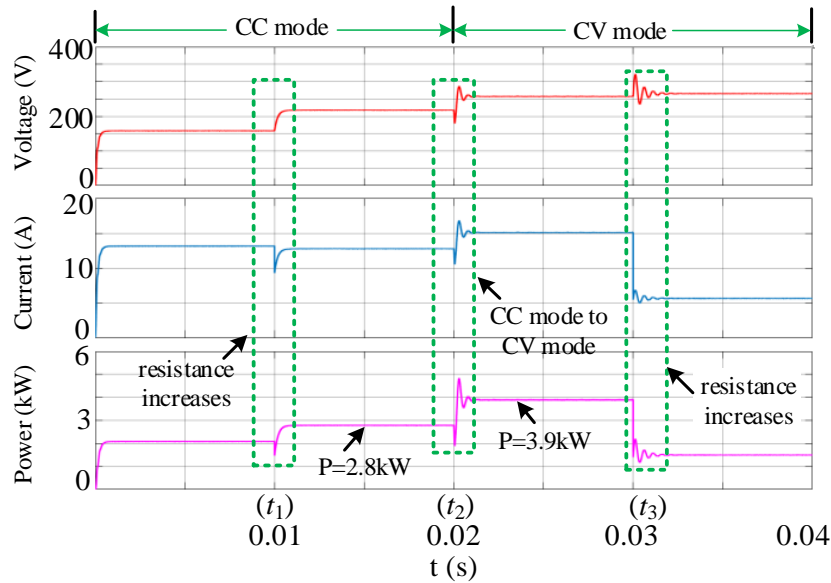

(b)

Figure 11. Charging process under $t_{1}$ : Increasing the resistance. $t_{2}$ : Switching from CC mode to CV mode. $t_{3}$ : Increasing the resistance. (a) Constant rated output power during switching. (b) Changing rated output power during switching.

\subsection{Experimental Results}

Combined with the previous analysis, this paper established a $3.3 \mathrm{~kW}$ experimental platform as shown in Figure 12. The CC and CV transmission modes were realized by two SS topologies based on different combined bridge arms at $85 \mathrm{kHz}$.

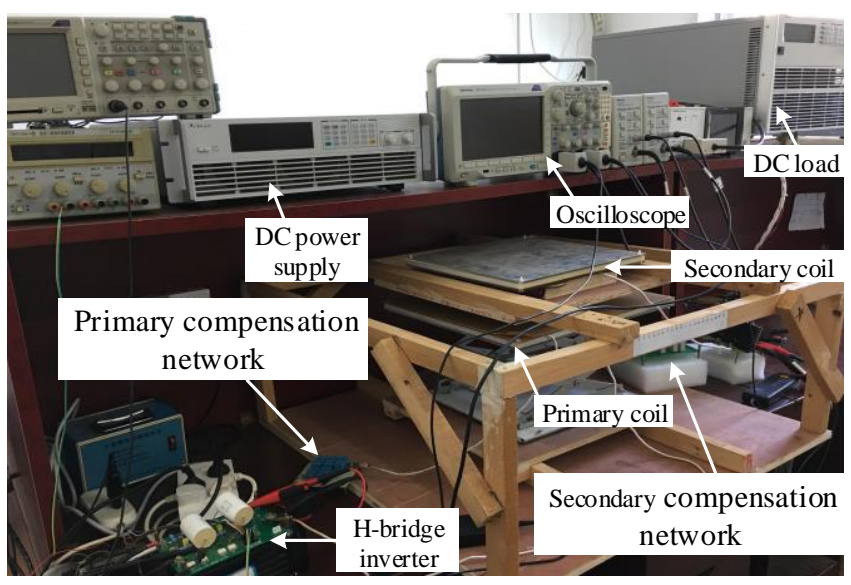

Figure 12. IPT system experiment platform. 
The Figure 13a shows the system working in CC mode, $u_{\mathrm{AB}}$ represents the inverter output voltage, $i_{\mathrm{AB}}$ represents the inverter output current, and $u_{\mathrm{gs}}$ represents the drive voltage of the switching tube. The Figure $13 \mathrm{~b}$ shows the system working in CV mode, $u_{\mathrm{BC}}$ represents the inverter output voltage, $i_{\mathrm{BC}}$ represents the inverter output current, and $u_{\mathrm{gs}}$ represents the drive voltage of the switching tube. It can be seen that Zero Voltage Switch (ZVS ) was implemented in the CV mode of the system, and there were ZVS trends in the CC mode.

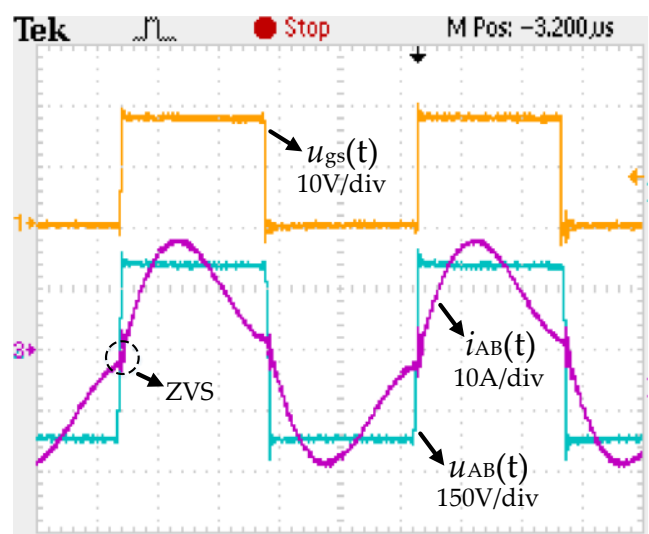

Time $2.5 \mu \mathrm{s} / \mathrm{div}$

(a)

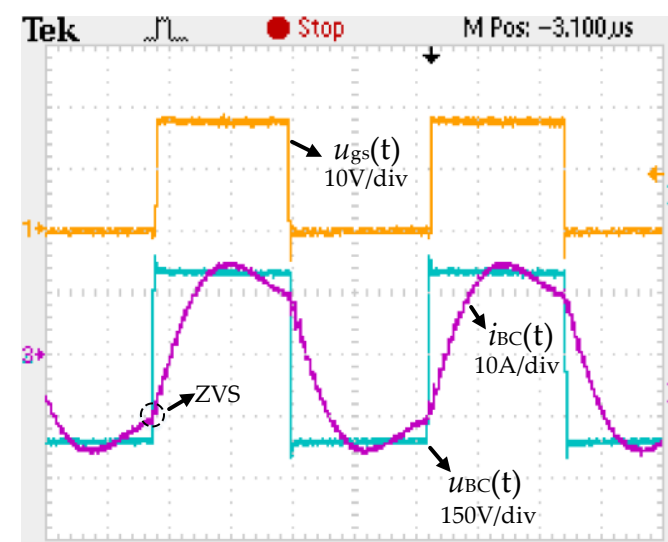

Time $2.5 \mu \mathrm{s} / \mathrm{div}$

(b)

Figure 13. Waveform of inverter output voltage/current and rectifier input voltage under the (a) CC transmission mode and (b) CV transmission mode.

As shown in Figure 14a, the load was switched from half to full at $t_{\mathrm{cc} 1}$ and then back to half at $t_{\mathrm{cc} 2}$. As shown in Figure 14b, the load was switched from half to full at $t_{\mathrm{cv} 1}$ and then back to half at $t_{\mathrm{cv} 2}$. According to the experimental results of the system output voltage and current in Figure 14, the validity of the previous analysis with the $\mathrm{CC} / \mathrm{CV}$ transmission characteristics can be verified.

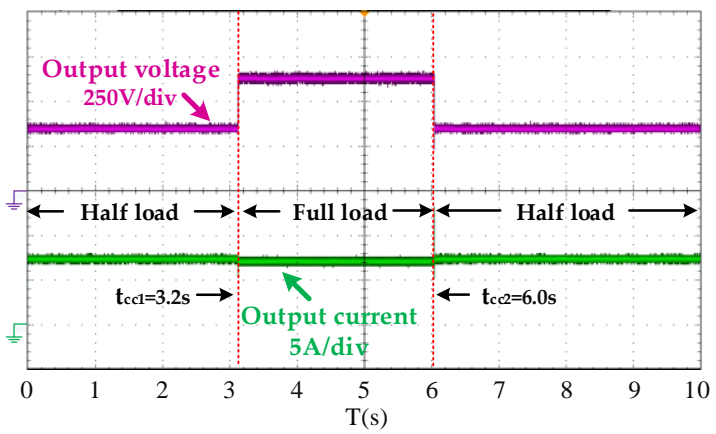

(a)

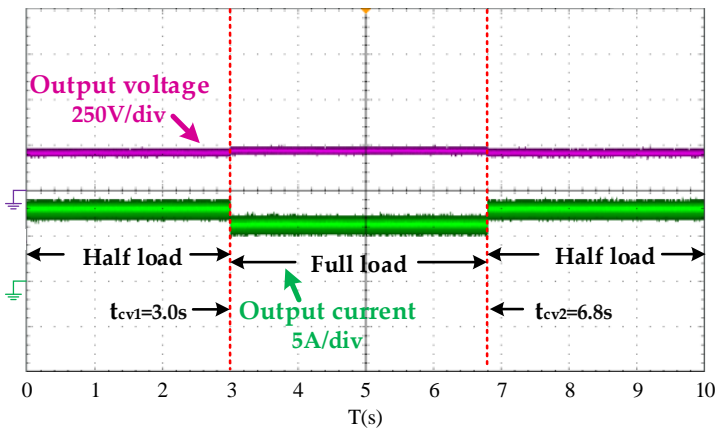

(b)

Figure 14. Output voltage and current of IPT system with (a) CC transmission mode and (b) CV transmission mode.

Figure 15 shows the experimental efficiencies of the three-bridge IPT system versus different output powers. It can be seen that in a certain range, the system efficiency was increasing with the output power in both CC and CV mode. In addition, the system efficiencies at rated output power were $92.04 \%$ and $91.21 \%$ in CC and CV mode, respectively. 


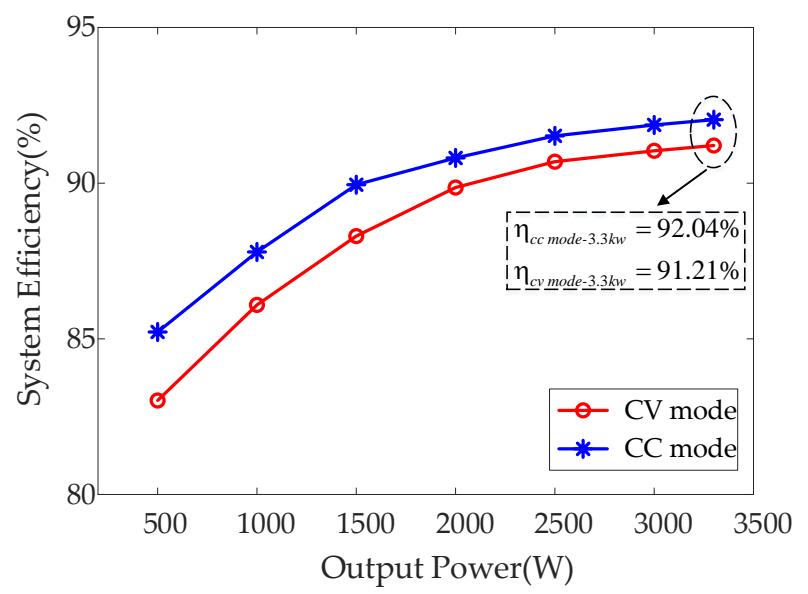

Figure 15. Experimental efficiencies of the IPT system versus output power in both CC and CV output modes.

\section{Conclusions}

This paper proposed a three-bridge IPT system, which could realize the CC/CV mode transmission under the fixed-frequency by topology parameter design and convert from CC to CV mode by switching the working arm. On this basis, by designing the rated load resistance at the switching time, the specific output powers before and after the switching time were realized. Therefore, the effectiveness of $\mathrm{CC} / \mathrm{CV}$ mode switching and the output of different powers by switching the bridge arms was verified. By establishing and analyzing the leakage inductance equivalent model based on SS topology, the resonance condition of the $\mathrm{CC} / \mathrm{CV}$ mode transmission characteristics were obtained. Finally, circuit simulations and the corresponding experiment were built, which verified the theoretical analysis and the effectiveness of this structure.

Author Contributions: Conceptualization, M.L. and J.L.; data curation, Y.S. and M.L.; project administration, X.D. and B.L.; resources, G.Z.; supervision, G.Z.; validation, X.D.; writing-review and editing, Y.S. and J.L.

Funding: This research was funded by National Natural Science Foundation of China grand number 51777146 and the Science and Technology Foundation of Guizhou province in China (No. LH-[2014]7369)

Conflicts of Interest: The authors declare no conflict of interest.

\section{References}

1. RamRakhyani, A.K.; Mirabbasi, S.; Chiao, M. Design and Optimization of Resonance-Based Efficient Wireless Power Delivery Systems for Biomedical Implants. IEEE Trans. Biomed. Circuits Syst. 2011, 5, 48-63. [CrossRef] [PubMed]

2. Li, Q.; Liang, Y.C. An Inductive Power Transfer System with a High-Q Resonant Tank for Mobile Device Charging. IEEE Trans. Power Electron. 2015, 30, 6203-6212. [CrossRef]

3. Beh, H.Z.Z.; Covic, G.A.; Boys, J.T. Investigation of Magnetic Couplers in Bicycle Kickstands for Wireless Charging of Electric Bicycles. IEEE J. Emerg. Sel. Top. Power Electron. 2015, 3, 87-100. [CrossRef]

4. Zhang, W.; White, J.C.; Abraham, A.M.; Mi, C.C. Loosely Coupled Transformer Structure and Interoperability Study for EV Wireless Charging Systems. IEEE Trans. Power Electron. 2015, 30, 6356-6367. [CrossRef]

5. Villa, J.L.; Sallan, J.; Osorio, J.F.S.; Llombart, A. High-Misalignment Tolerant Compensation Topology for ICPT Systems. IEEE Trans. Ind. Electron. 2012, 59, 945-951. [CrossRef]

6. Khaligh, A.; Dusmez, S. Comprehensive Topological Analysis of Conductive and Inductive Charging Solutions for Plug-In Electric Vehicles. IEEE Trans. Veh. Technol. 2012, 61, 3475-3489. [CrossRef]

7. Sallan, J.; Villa, J.L.; Llombart, A.; Sanz, J.F. Optimal Design of ICPT Systems Applied to Electric Vehicle Battery Charge. IEEE Trans. Ind. Electron. 2009, 56, 2140-2149. [CrossRef]

8. Gerssen-Gondelach, S.J.; Faaij, A.P.C. Performance of batteries for electric vehicles on short and longer term. J. Power Sour. 2012, 212, 111-129. [CrossRef] 
9. Qu, X.; Han, H.; Wong, S.; Tse, C.K.; Chen, W. Hybrid IPT Topologies With Constant Current or Constant Voltage Output for Battery Charging Applications. IEEE Trans. Power Electron. 2015, 30, 6329-6337. [CrossRef]

10. Yilmaz, M.; Krein, P.T. Review of Battery Charger Topologies, Charging Power Levels, and Infrastructure for Plug-In Electric and Hybrid Vehicles. IEEE Trans. Power Electron. 2013, 28, 2151-2169. [CrossRef]

11. Gati, E.; Kampitsis, G.; Manias, S. Variable Frequency Controller for Inductive Power Transfer in Dynamic Conditions. IEEE Trans. Power Electron. 2017, 32, 1684-1696. [CrossRef]

12. Buja, G.; Bertoluzzo, M.; Mude, K.N. Design and Experimentation of WPT Charger for Electric City Car. IEEE Trans. Ind. Electron. 2015, 62, 7436-7447. [CrossRef]

13. Lu, J.; Zhu, G.; Shou, Y.; Liu, F. Coupling- and Load-Independents Output Voltage and ZPA Operation in LCC-Series Compensated IPT System. In Proceedings of the 2018 IEEE Energy Conversion Congress and Exposition (ECCE), Portland, OR, USA, 23-27 September 2018; pp. 1172-1176.

14. Lu, J.; Zhu, G.; Wang, H.; Lu, F.; Jiang, J.; Mi, C.C. Sensitivity Analysis of Inductive Power Transfer Systems With Voltage-Fed Compensation Topologies. IEEE Trans. Veh. Technol. 2019, 68, 4502-4513. [CrossRef]

15. Rahnamaee, H.R.; Madawala, U.K.; Thrimawithana, D.J. A modified hybrid multi-level converter for high-power high-frequency IPT systems. In Proceedings of the 2014 International Power Electronics and Application Conference and Exposition, Shanghai, China, 5-8 November 2014; pp. 624-629.

16. Li, Y.; Mai, R.; Lu, L.; He, Z.; Liu, S. Harmonic elimination and power regulation based five-level inverter for supplying IPT systems. In Proceedings of the 2015 IEEE PELS Workshop on Emerging Technologies, Wireless Power (2015 WoW), Daejeon, South Korea, 5-6 June 2015; pp. 1-4.

17. Cheng, C.; Zhou, Z.; Li, W.; Zhu, C.; Deng, Z.; Mi, C.C. A Multi-Load Wireless Power Transfer System With Series-Parallel-Series Compensation. IEEE Trans. Power Electron. 2019, 34, 7126-7130. [CrossRef]

18. Liu, F.; Yang, Y.; Ding, Z.; Chen, X.; Kennel, R.M. A Multifrequency Superposition Methodology to Achieve High Efficiency and Targeted Power Distribution for a Multiload MCR WPT System. IEEE Trans. Power Electron. 2018, 33, 9005-9016. [CrossRef]

19. Lu, J.; Zhu, G.; Lin, D.; Wong, S.; Jiang, J. Load-Independent Voltage and Current Transfer Characteristics of High-Order Resonant Network in IPT System. IEEE J. Emerg. Sel. Top. Power Electron. 2019, 7, 422-436. [CrossRef]

(C) 2019 by the authors. Licensee MDPI, Basel, Switzerland. This article is an open access article distributed under the terms and conditions of the Creative Commons Attribution (CC BY) license (http://creativecommons.org/licenses/by/4.0/). 